“ (C) 2017 IEEE. Personal use of this material is permitted. Permission from IEEE must be obtained for all other uses, in any current or future media, including

reprinting/republishing this material for advertising or promotional purposes, creating new collective works, for resale or redistribution to servers or lists, or reuse of any copyrighted component of this work in other works." 


\title{
Design, Analysis and Control of a Magnetically-coupled Multi-port Multi-operation-Mode Residential Micro-grid
}

\author{
Mohammad Jafari, Memebr, IEEE, Zahra Malekjamshidi, and Jianguo Zhu, Senior Member, IEEE \\ University of Technology Sydney, PO Box 123, Broadway, Sydney, Australia
}

\begin{abstract}
This paper proposes topology of a magnetically coupled residential micro-grid consisting of a multi-port dc-dc converter and a single phase grid-connected bidirectional inverter. It integrates photovoltaic (PV) and fuel cell energies to supply the residential load via a common high-voltage de bus linked to a single phase bidirectional inverter. A battery is used to store the surplus energy of the system and stabilize the bus voltage of the fuel cell port. The multi-port converter includes a three port phase shift converter for integrating renewable sources, a bidirectional buck-boost converter for charging and discharging the battery and an interleaved boost converter for boosting the PV voltage and maximum power point tracking. Using interleaved topology has reduced the effects of both high frequency current ripple and low frequency voltage ripple propagated from inverter on the maximum power point tracking (MPPT) performance. The steady state operation and control strategy of the proposed micro-grid are discussed and simulation results are presented.
\end{abstract}

Index Terms- Dc-dc converter, bidirectional power flow, multi-port, phase shift, residential micro-grid.

\section{INTRODUCTION}

$\mathbf{O}$ VER the past century, the average global air temperature at the earth surface has been raised for about $0.74{ }^{\circ} \mathrm{C}$, which has generated serious concerns about the global warming and consequent environmental problems [1]. Some studies suggested that this is mainly caused by the excessive use of various fossil fuels, such as oil and coal. Therefore, the demand for environment friendly sustainable energy sources has increased significantly over the past decades. The electricity generation as one of the major contributors to environmental pollution should undergo a fundamental change towards clean energy sources. Therefore renewable energy resources have attracted a great interest during the past decades. To integrate the renewable energies different converter topologies and micro-grid structures are proposed in the literatures. Multi-port converters (MPCs) have attracted much research attention in recent years [2]-[5]. The phase shift MPC's have presented excellent performances for integration of renewable energy systems. In contrast to other topologies they provide attractive features such as isolation between the ports, bidirectional power flow, simple power flow and energy management control, lower switching stress and efficient use of transformer leakage inductance as energy transfer element [6]-[8]. To link the low voltage sources such as PV, fuel cell and the batteries to the common micro-grid bus, boost or buckboost converters are the most common conversion topologies The boost dc-dc converters have been conventionally used to step up the PV output voltage and utilize maximum power point tracking (MPPT) [9], [10]. On the other hand, to control the charge and discharge of battery in the micro-grid, bidirectional buck-boost dc-dc converters have been widely used [11], [12].

The residential micro-grid proposed in this paper employs a combination of $\mathrm{dc}$ bus and magnetic bus to integrate the energies of a PV panel, fuel cell and a battery to supply the local loads. It includes a triple active bridge (TAB) phase shift dc-dc converter, an interleaved current-fed boost converter for PV connection and MPPT, a bidirectional buck-boost dc-dc converter for battery port and a single phase bidirectional inverter. A detailed study of the steady state operation of micro-grid and the controller design of the converters is provided.

\section{STEADY STATE OPERATION OF THE PROPOSED MICRO-GRID}

The structure of the proposed micro-grid is presented in Fig.1. The micro-grid is designed to supply a $5 \mathrm{~kW}$ residential load from combined energy sources of a PV array, a fuel cell stack, and a battery bank. As shown in the figure, the microgrid structure includes a triple active bridge (TAB) dc-dc converter which couples ports one, two, and three, a bidirectional buck-boost converter as battery port (Port four) and an interleaved boost converter as PV port (Port three). Port one is a bi-directional port and transfers the power from the renewable sources or battery to the inverter and further to the load and grid. It also operates in the reverse direction to transfer the power from the grid to the battery (using the ports two and four simultaneously). The fuel cell stack is used as the backup energy source and the PV is considered as the preferred source to supply the load and possibly the grid. The battery is used as the energy storage device and also balances the voltage of dc bus due to the slow dynamic response of the fuel cell. It also handles the quick start up which lets the fuel cell warm up. The single phase inverter is designed to link the proposed micro-gird to the main grid.

The proposed micro-grid is able to operate in different operation modes based on the power flow directions and energy management scenarios. It is controlled by two digital signal processors (DSPs) at the device level and a PC system as the energy management unit (EMU) at the system level. The EMU defines the appropriate operation mode of the system based on the real-time value of system parameters, energy generation and consumption forecasts and long-term energy plans. A fuzzy logic controller is designed as the main decision maker of EMU. It also communicates with the regional distribution network control center using internet to receive the metrological data and grid connection control signals. This paper only studies the devise level controllers and converter design. Details of fuzzy logic based EMU and power flow control remains for future publications. 

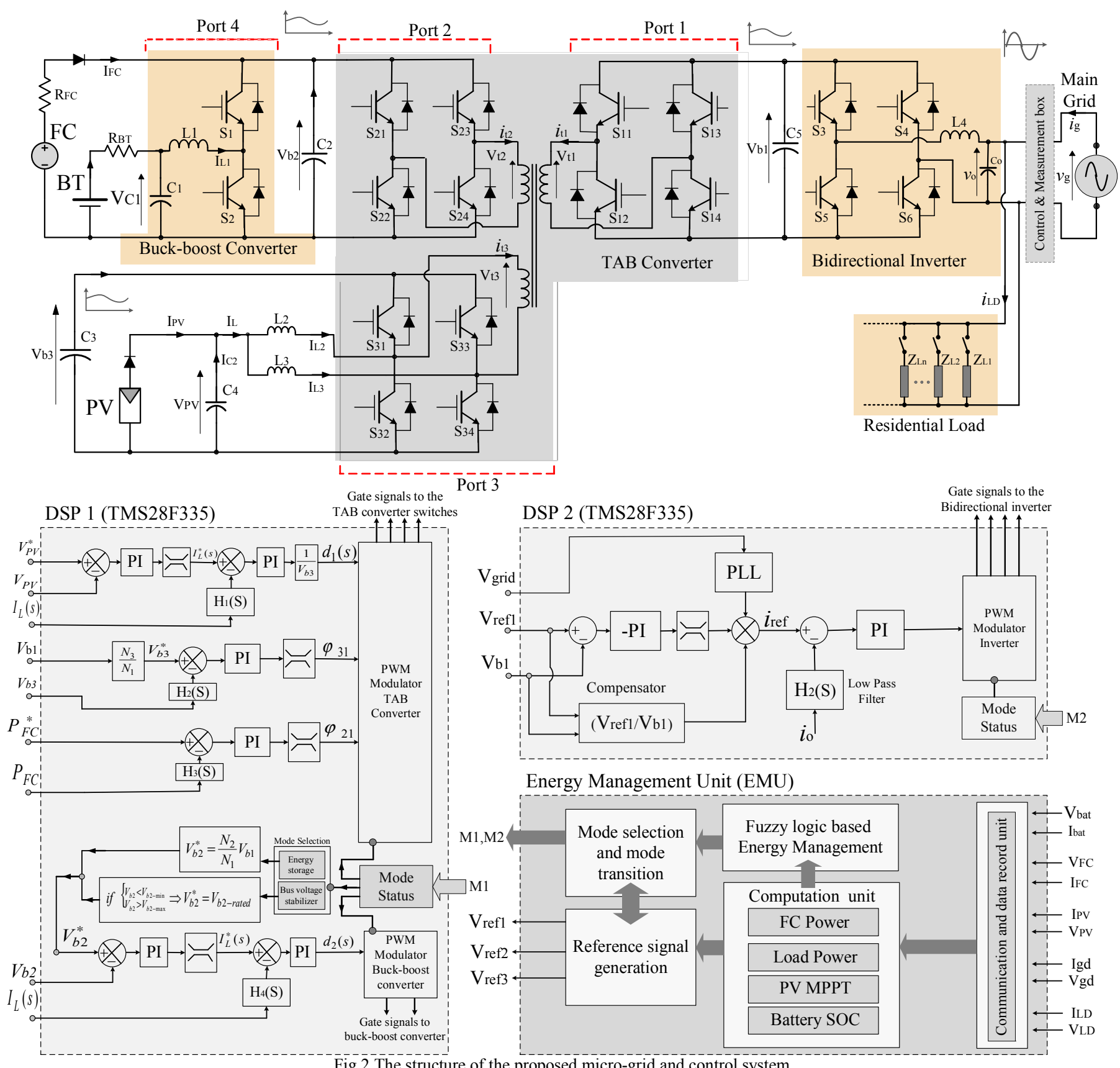

Fig.2. The structure of the proposed micro-grid and control system

As can be seen in the figure, a three winding transformer is used as a magnetic bus to link the converter ports. The highfrequency square waves generated by the H-bridge inverters in each port are applied to the windings of the magnetic link. The power flow between port one, two and three is controlled by introducing leading or lagging phase shifts between the high frequency square waves of the ports. The DC high voltage on the inverter port $V_{b l}$, should be kept constant during normal operation of converter as a regulated voltage is required to supply the inverter and consequently output loads. The power transferred between ports two and one in the proposed TAB converter considering constant duty cycle at Port one and two $\left(D_{1}=D_{2}=1\right)$, can be found from [3], [4]

$$
P_{21}=\frac{V_{b 2} V_{b 1}}{2 n_{21} \pi f L_{21}} \varphi_{21}\left(1-\frac{\left|\varphi_{21}\right|}{\pi}\right)
$$

where $L_{21}$ is the summation of leakage inductance of winding one and referred value of leakage inductance of winding two to winding one. $f$ is the switching frequency and $n_{21}$ is turns ratio of winding two to one. The power transferred from port three to port one, $P_{31}$, due to the duty ratio control on Port three (PV port) depending on the variation range of $\varphi_{31}$ can be defined as Mode $I: P_{31}=\frac{V_{b 3} V_{b 1}}{2 \pi f n_{31} L_{31}}\left[\begin{array}{l}\varphi_{31}\left(1-\frac{\left|\varphi_{31}\right|}{\pi}\right)- \\ \operatorname{sign}\left(\varphi_{31}\right)\left[\frac{\pi}{4}\left(1-D_{3}\right)^{2}\right]\end{array}\right]$, for $\varphi_{31}>\varphi_{B}$

Mode II $: P_{31}=\frac{V_{b 3} V_{b 1}}{2 \pi f n_{31} L_{31}} D_{3} \varphi_{31}$, for $-\varphi_{B} \leq \varphi_{31} \leq \varphi_{B}$

where $\varphi_{B}=\pi\left(1-D_{3}\right) / 2$ is the boundary phase shift angle. As there are only two independent variables known as $\varphi_{21}$ and $\varphi_{31}$ therefore, $\varphi_{32}$ is redundant and can be written based on the other phase shift angles as $\varphi_{32}=\varphi_{31}-\varphi_{21}$ [3]. Due to this the power flow between port two and three $P_{32}$ can be defined by

$$
\begin{gathered}
\text { Mode I: } P_{32}=\frac{V_{b 3} V_{b 2}}{2 \pi f n_{32} L_{32}}\left[\begin{array}{l}
\left(\varphi_{31}-\varphi_{21}\right)\left(1-\frac{\left|\left(\varphi_{31}-\varphi_{21}\right)\right|}{\pi}\right) \\
-\operatorname{sign}\left(\varphi_{31}-\varphi_{21}\right)\left[\frac{\pi}{4}\left(1-D_{3}\right)^{2}\right]
\end{array}\right], \text { for }\left|\left(\varphi_{31}-\varphi_{21}\right)\right|>\varphi_{B} \\
\text { Mode II }: P_{32}=\frac{V_{b 3} V_{b 2}}{2 \pi f n_{32} L_{32}} D_{3}\left(\varphi_{31}-\varphi_{21}\right), \text { for }\left|\left(\varphi_{31}-\varphi_{21}\right)\right| \leq \varphi_{B}
\end{gathered}
$$


where $\varphi_{B}$ and $n_{32}$ are defined similar to (2).

The bidirectional buck-boost converter is used to transfer the power between the battery and other sources through a charging or discharging process. To combine both step up and step down conversion stages in a single power stage, the inductor $L_{1}$ is shared in both buck and boost operation modes. The converter operation during both charge and discharge modes is similar and the only difference is in the duty cycles of drive signals of $S_{1}$ and $S_{2}$. Operation in the buck (charging) mode or the boost (discharging) mode is determined by the duty ratio of the switching drive signal which is defined by ratio of the bus voltage, $V_{\mathrm{b} 2}$ to the battery voltage $V_{\mathrm{BT}}$. The range of duty ratio variation in charge or discharge operation modes is defined according to a critical duty ratio $D_{2}^{*}$, where the inductor average current is equal to zero. The critical duty ratio $D_{2}^{*}$ is defined as

$$
D_{2}^{*}=\frac{V_{B T}^{*}}{V_{b 2}^{*}}
$$

where $V_{B T}^{*}$ and $V_{b 2}^{*}$ are the nominal value of battery and bus voltages respectively. The converter operates in the buck $\left(D>D_{2}^{*}\right)$, boost $\left(D<D_{2}^{*}\right)$ or in the boundary between buck and boost $\left(D=D_{2}^{*}\right)$. The gate signals of $\mathrm{S}_{1}$ and $\mathrm{S}_{2}$ are complementary and a dead time $t_{d t}$ is introduced between turn off time of one switch to turn on time of the other. The inductor current depends on the battery voltage $V_{\mathrm{BT}}$ and fuel cell voltage $\mathrm{V}_{\mathrm{FC}}$ and can be defined as

$$
I_{L 1}=\frac{D \cdot V_{F C}-V_{B T}}{D^{2} \cdot R_{F C}+R_{B T}+r_{L 1}}
$$

where $R_{F C}, R_{B T}$ and $r_{L 1}$ are the internal resistance of fuel cell, battery and inductor $L_{l}$ respectively.

The interleaved boost converter boosts the output voltage of the PV to the desired range $(100-110 \mathrm{~V})$. The interleaved topology reduces the generated ripple on the PV output current and effectively adjusts the operation point of the PV on maximum power point (MPP). The generated square wave on the PV port has a variable duty cycle due to the MPPT process and variations of duty cycles of $S_{31}-S_{34}$ switches. On the other hand, to maintain a full range of ZVS operation for all converter ports, the volt-second product on all windings of the magnetic link should be kept equal [2]. Therefore, the phase shift angle $\varphi_{31}$, is used as control variable to adjust the bus voltage $V_{b 3}$ on the PV port as illustrated in Fig.1. The duty ratio of port three varies according to the amplitude of PV output voltage $V_{P V}$, and the dc bus voltage $V_{b 3}$ and is defined as

$$
D_{3}=\left\{\begin{array}{cl}
\frac{2 V_{P V}}{V_{b 3}} & V_{b 3}>2 V_{P V} \\
2\left(1-\frac{V_{P V}}{V_{b 3}}\right) & V_{b 3}<2 V_{P V}
\end{array}\right.
$$

The reference voltage $V_{b 3}^{*}$ considering equal volt-second product principle applied to the transformer turns ratio is defined by

$$
V_{b 3}^{*}=\frac{N_{3}}{D_{3} N_{1}} V_{b 1}
$$

In the case of fuel cell port, there are two operation modes. In the first mode only fuel cell is operating as active source and battery is in standby condition and operates as bus voltage stabilizer. It is activated only when the bus voltage goes outside of a predefined bus voltage range and brings it back to the standard range. The bus reference voltage $V_{b 2}^{*}$ in this case is either the maximum or minimum values of bus voltage. In the second case where battery is the only active component, the reference voltage is defined according to the dc bus voltage synchronizing rule and is defined from

$$
V_{b 2}^{*}=\frac{N_{2}}{N_{1}} V_{b 1}
$$

The DC high voltage on the inverter bus is regulated by bidirectional inverter according to the reference value defined by EMU as presented in Fig.1.

\section{DESIGN OF CONTROLLER FOR THE PROPOSED MICRO-GRID}

To design a control system for the proposed micro-grid, small signal models of converters are required. Details on the small signal modelling of the converters and extracting transfer functions will be provided in the future publications. In this section only a review on the design of the controller for each converter is provided.

There are two main objectives in the design of controller for the TAB converter. They are, firstly regulation of voltage on PV bus $V_{\mathrm{b} 3}$, by adjusting $\varphi_{31}$ to transfer the power to the port one. This also maintain the equal volt-second across windings of the magnetic link to realize a full range soft-switching operation. The second objective is to adjust the fuel cell power on the referenced value by adjusting $\varphi_{21}$. It should be noted that the fuel cell reference power is defined by EMU according to the energy management scenario. The fuel cell reference power can be adjusted to cover the difference between PV and load power or just a portion of load power or to send a certain value of power to the main grid. Fig.2 illustrates the control to output block diagram of the $\mathrm{TAB}$ converter and closed loop PI controllers. The TAB converter small signal model including direct $\left(G_{11}\right.$ and $\left.G_{22}\right)$ and coupling $\left(G_{12}\right.$ and $\left.G_{21}\right)$ transfer functions is used to model the relation between control variables $\left(\varphi_{21}\right.$ and $\left.\varphi_{31}\right)$ and control outputs $\left(V_{b 3}\right.$ and $\left.P_{F C}\right)$. As can be seen, the voltage on PV port, $V_{b 3}$, is used as the feedback signal, and is compared with the reference value obtained from applying volt-second rule equality to the windings. On the other hand, the output power of fuel cell is used as power-regulation feedback signal and is compared with the reference value defined by EMU. The voltage control and power control loops should operate independently and their cross-coupling effects should be reduced as much as possible. Therefore, the effects of coupling transfer functions in the TAB converter model, $\mathrm{G}_{23}$ and $\mathrm{G}_{32}$, should be compensated by decoupling transfer functions added to the control loop. Another method is selection of different bandwidth of frequency response which results in different speeds of dynamic response for the voltage and power regulation loops. In this case the interaction between two control loops is minimized. In the first method, the decoupling transfer functions need real-time update and computational efforts which makes the control system more complex. Therefore, it is preferred to use the second method which is simpler for design and implementation. The bandwidth of voltage control closed loop frequency response is designed higher than that of fuel cell power regulation. Therefore, the voltage control loop has higher dynamic response compared with the fuel cell power regulation loop.

The small signal model of the bidirectional buck-boost converter and design of a closed loop control have been studied in the literatures [14]-[17]. To find the small signal averaged model, the high frequency effects of voltage sources including battery and fuel cell on the converter model should be taken into account and their high frequency model needs to be studied [18]. 


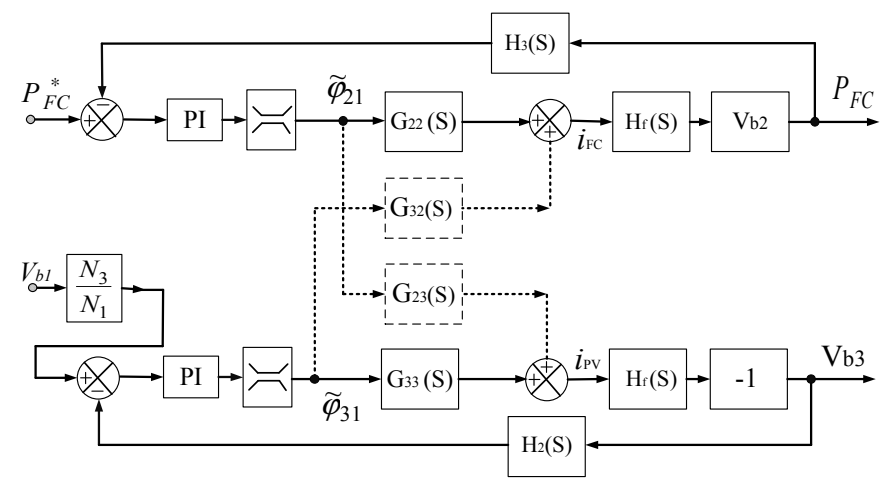

Fig.2. Block diagram of TAB converter control system

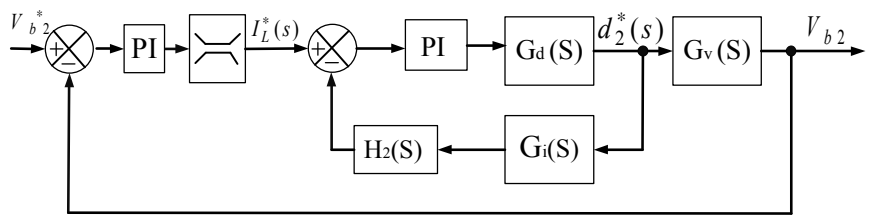

Fig.3. The double loop control diagram of bidirectional buck-boost converter

Study on high frequency models of the battery and fuel cell shows that their high frequency model can be simplified to a constant voltage source in series with a resistance. To design a control system for the bi-directional converter, a dual loop PI controller is considered. The dual loop PI controllers have a simple structure and have presented high performance in the control of buck-boost converters [15], [16]. The dual loop control diagram for the proposed buck-boost converter is presented in Fig.3. As can be seen it includes an outer voltage control and an inner current control loops to regulate the dc bus voltage precisely. In this structure the outer voltage loop provides a reference for the inner current loop. The $C_{v}(s)$ and $C_{i}(s)$ blocks are the continuous-time PI controllers of the voltage and current loops respectively. The time delay, $T_{d}$, caused by computational functions is represented in the loop as $G_{d}(s)$ and is equal to

$$
G_{d}(s)=e^{-s T_{d}}
$$

The transfer functions of the inductor current, $G_{i d}(s)$, and the bus voltage, $G_{v d}(S)$, to the duty ratio are obtained. The current and voltage loop transfer functions are required for stability analysis of the converter. The PI controller transfer functions are defined as

$$
C_{i}(s)=K_{i}\left(1+\frac{1}{\tau_{i} s}\right), C_{v}(s)=K_{v}\left(1+\frac{1}{\tau_{v} s}\right)
$$

where $K_{i}$ and $K_{v}$ are proportional and integral gains and $\tau_{i}$ and $\tau_{v}$ are the current loop and voltage loop controller time constants respectively. The controller gains are defined according to the required cross over frequency and phase margin of the voltage and current loop transfer functions. [15][17]. The inner current loop should be designed to present higher speed compared with the outer voltage loop to avoid interaction between loop operations [16],[17].

In the PV port, the H-bridge switches $S_{31}, S_{32}, S_{33}$ and $S_{34}$ have been shared in both interleaved boost and TAB dc-dc converters. The capacitor $C_{3}$ is used as an energy buffer between the two conversion stages. Therefore, the PV port can be modelled as an interleaved boost converter cascaded by a voltage source dc-ac H-bridge converter. The output voltage from PV is adjusted on MPP by duty cycle variation of the drive signals of $S_{31}$ and $S_{34}$ while the dc bus voltage, $V_{b 3}$, is controlled by the phase shift angle, $\varphi_{31}$.

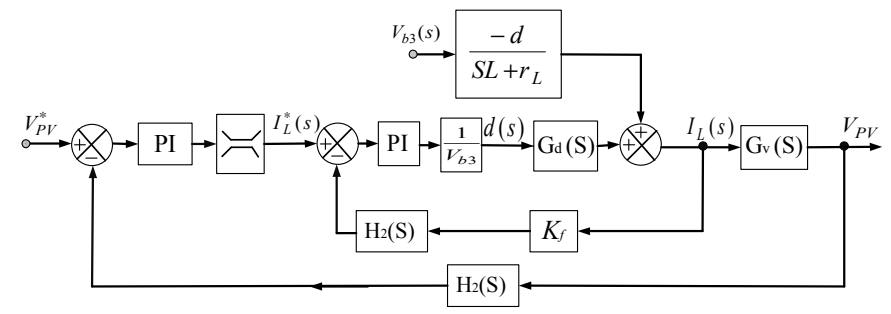

Fig.4. The dual loop control diagram of the PV voltage and inductor current

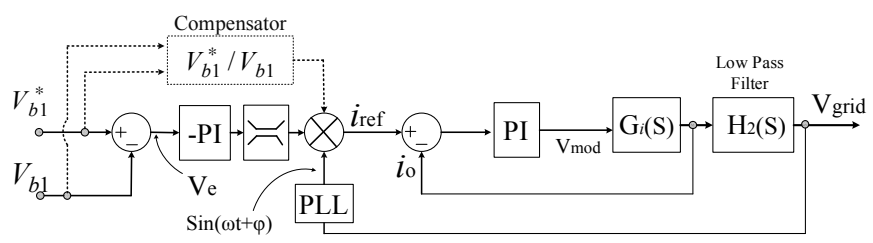

Fig.5. The control scheme of bidirectional inverter

The operation range of the PV port depends on the variation range of duty ratio $D_{3}$ and phase shift angle $\varphi_{31}$ (from 0 to $\pi$ ). In the proposed converter the practical phase shift angle is less than $\pi / 2$, and the duty cycle, is changed around 0.5 to achieve higher efficiency. The ZVS operation range of the switching devices on PV port is in a limited range although in the case of equal volt-second for all windings of the magnetic link, ZVS operation is guaranteed for other two ports of the TAB converter [3]. To design the PV voltage controller, small signal model of both the PV port and interleaved boost converter are obtained. To design a more robust controller for adjusting the PV voltage on MPP, a dual loop control system including inner current loop which controls the inductor current $I_{L}$, and outer voltage loop which controls the PV capacitor voltage according to the MPPT control command [13]. The proposed dual loop control diagram is presented in Fig.4. The bandwidth of inner current loop should be selected much higher than the PV voltage control loop. In this case the PV voltage control loop does not need to react against the high frequency voltage ripples. Therefore a low bandwidth control loop with more robustness and stability can be used. In the proposed control loop, $H_{1}(s)$ and $H_{2}(s)$ are the transfer functions of low-pass first-order filters that filter out the high frequency components of PV output voltage $v_{\mathrm{PV}}$ and inductor current $i_{\mathrm{L}}$ respectively and can be defined as

$$
H_{1}(s)=\frac{1}{1+\tau_{1} s}, H_{2}(s)=\frac{1}{1+\tau_{2} s}
$$

where $\tau_{1}$ and $\tau_{2}$ are the time constants of the filters. The feedback gain of $K_{f}$ is selected according to the signal conditioning circuit parameters. $C_{v}$ and $C_{i}$ are the PI controller transfer functions. Comparing the bandwidths of the voltage and current control loops shows that the current loop control has higher speed response compared with the voltage loop.

The proposed micro-grid is connected to the main grid by a bidirectional inverter as presented in Fig.1. The designed micro-grid should be able to operate in both grid-connected and islanding conditions. It is designed to switch to islanding condition when the utility grid is not available or there is an accidental power outage. In the proposed inverter a direct current-control strategy is used to force the instantaneous output current to follow the provided sinusoidal reference voltage [19]. The referenced voltage is synchronized with the grid voltage in grid connected condition by using a PLL block or generated independently in off-grid mode. The direct current control technique provides high power factor, low THD and fast dynamic response [19]. The bidirectional power flow 
ability is achieved by changing the dc bus voltage reference $V_{b 1}^{*}$. The bidirectional power flow enables the inverter to operate in the rectifier mode and transfers energy from grid to the multi-port dc-dc converter and further to the battery. It also can be used to compensate for the voltage fluctuations of the high voltage dc-bus which improves the stability of $V_{b 1}$ (especially at the startup time) and of the overall micro-grid system. The inverter control loop is presented in Fig.5. As can be seen, the dc voltage of inverter bus, $V_{\mathrm{b} 1}$, is compared with a predefined reference voltage, $V_{b 1}^{*}$ and is forced to follow the reference with zero error by using the control loop. The amplitude and direction of power through the inverter is controlled by the output current. The direction of the current and power flow is defined according to the value of $V_{\mathrm{e}}$ which is the output of the negative PI controller in the voltage control loop. In the case of $V_{b 1}>V_{b 1}^{*}, V_{\mathrm{e}}$ is positive and increasing which allows the converter to operate as an inverter and to transfer power from renewables to the load and grid. On the other hand, when $V_{b 1}<V_{b 1}^{*}$, the resultant value of $V_{\mathrm{e}}$ is negative and decreasing which forces the converter to work as a PWM rectifier. In this case, the power flows from the utility grid to the high voltage dc bus and further to the battery port to charge the battery. This mode also can be used at the start up time of the multi-port converter to reduce the inrush current and facilitate the soft start. Maintaining a constant voltage on the inverter bus also improves the bus voltage synchronization which reduces the harmonics of the $\mathrm{TAB}$ converter currents and minimizes the rms, average and peak values of currents in the windings of the magnetic link. The output current $i_{o}$, is compared with the reference current, $i_{r e f}$, and the resultant error signal is sent to the PI controller in the current control loop. To avoid instabilities in the double loop control, the crossing frequency of current control loop is designed to be higher than that of voltage control loop. In this case, the inner current loop operates in higher speed compared with the voltage loop.

A common problem in grid-tied inverters is the appearance of a voltage ripple with the frequency $2 \omega$ on the dc bus voltage [13],[19].Therefore, a compensation block is added to the designed voltage control loop as a feed forward input. The compensation block which is equal to $V_{b 1}^{*} / V_{b 1}$, applies a reverse fluctuating signal with frequency $2 \omega$ to the inductor current to compensate the ripple on the dc bus [19].

\section{Simulation RESUlts}

The proposed micro-grid topology and the designed controllers are simulated using MATLAB. Fig. 6 shows the waveforms of the TAB converter for two different phase shift angle and duty cycles. Fig.7 presents the simulated waveforms of the interleaved boost converter for two different duty cycle values. Fig. 8 shows the wave forms of bidirectional buckboost-converter for operation in both buck and boost modes. The waveforms of voltage on switching devices ( $\mathrm{V}_{\mathrm{CE}-\mathrm{Q} 1}$ and $\mathrm{V}_{\mathrm{CE}-\mathrm{Q} 2}$ ), inductor current $\mathrm{I}_{\mathrm{L}}$ and the current flows through the fuel cell bus, $\mathrm{I}_{\text {bus }}$ are illustrated in the figures. The converter is operating in continuous conduction mode (CCM) and the average values of current in the inductor $\mathrm{I}_{\mathrm{L}}$ and the injected current from battery to the bus $\mathrm{I}_{\text {bus }}$ are positive in boost mode. therefore the battery is supplying the fuel cell bus. In the buck mode the battery is charging by fuel cell bus. As can be seen the converter is operating in CCM and the average value of inductor current and bus current are negative.
The dynamic performance of the micro-grid under the step change in the load and source is presented in Fig.9. The power flow performance of the micro-grid is simulated for two different cases. In the first case, the load power is supplied by both fuel cell and battery while the control objective is to keep the fuel cell power constant and the load variation only is compensated by battery. As can be seen in Fig.9 (a), the load power is reduced from $400 \mathrm{~W}$ to $200 \mathrm{~W}$ at $\mathrm{t}=50 \mathrm{~ms}$ and returned to the $400 \mathrm{~W}$ at $\mathrm{t}=100 \mathrm{~ms}$. The change in the load power is compensated by the battery while the power injected by the fuel cell remains unchanged at $200 \mathrm{~W}$ with slight overshoots at the step-change times. In the second case, the control objective is that the load power should be supplied by fuel cell and battery operates as a compensator during transients due to the slow dynamic response of fuel cell. As can be seen in the Fig.9 (b), the load power consumption is reduced from $200 \mathrm{~W}$ to $100 \mathrm{~W}$ at $\mathrm{t}=100 \mathrm{~ms}$ for a $100 \mathrm{~ms}$ time period. The fuel cell supplied power follows the load step change with a slow dynamic. It takes about $40 \mathrm{~ms}$ for fuel cell output power to be stabilized on the desired value and battery compensates the difference during the transients.

\section{CONCLUSION}

A topology of residential micro-grid using a common magnetic link for energy integration is presented in this paper. The steady state operation of the micro-grid and its control strategy was discussed. The DC-DC converters and the designed control loops are studied briefly and the simulation results are presented.
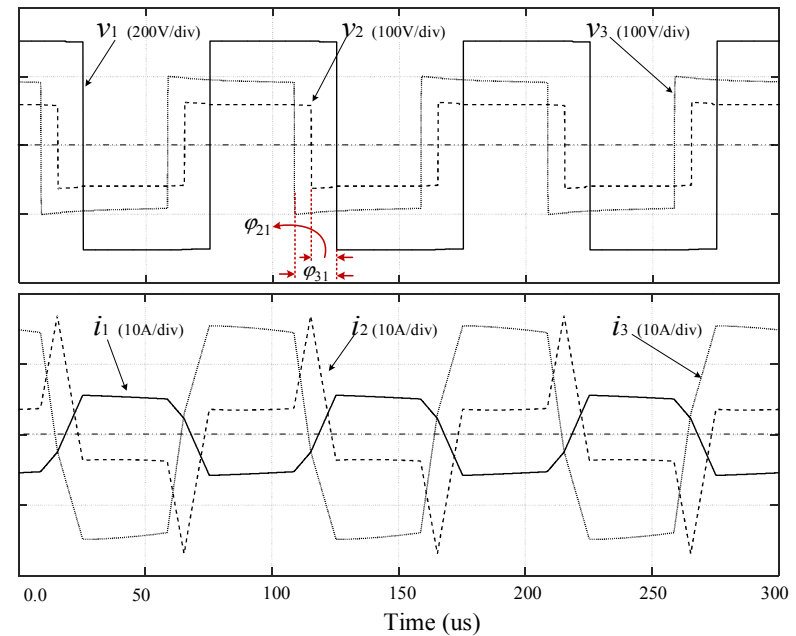

(a)
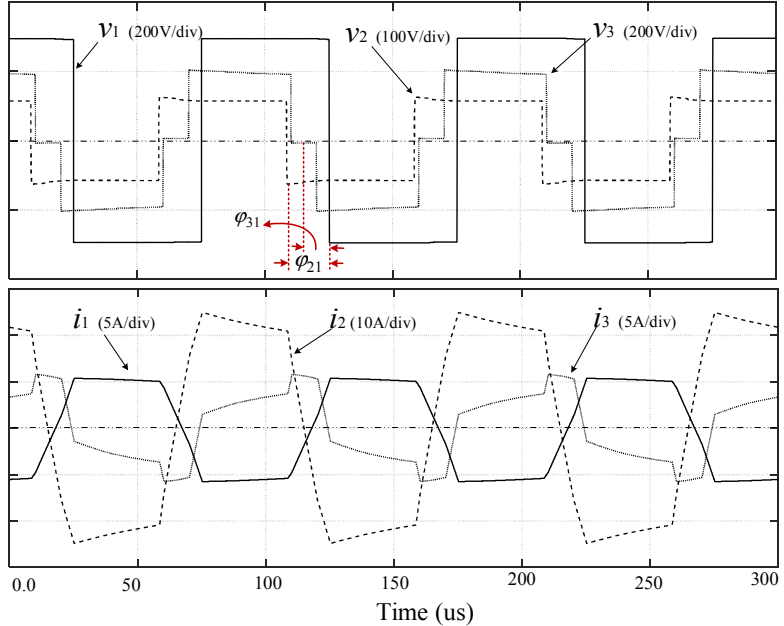

(b)

Fig.6. The simulated waveforms of the TAB converter for two different cases (a). $\mathrm{D}=1, \varphi_{31}=\pi / 3$ and $\varphi_{2 l}=\pi / 5$, and (b) $\mathrm{D}=0.8, \varphi_{31}=\pi / 5$ and $\varphi_{2 l}=\pi / 3$. 

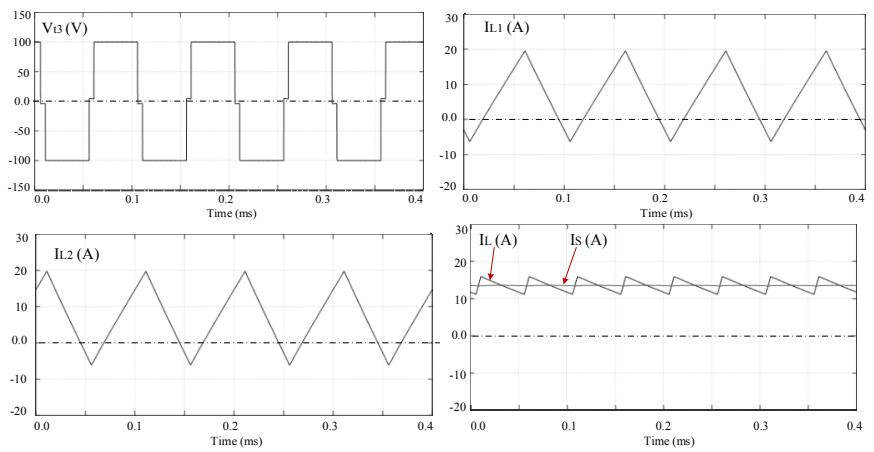

(a)

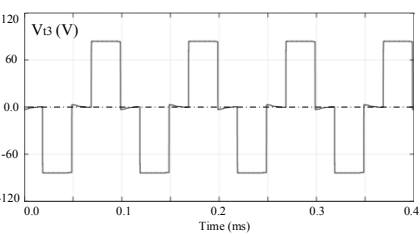

${ }^{21}$ IL1 (A)
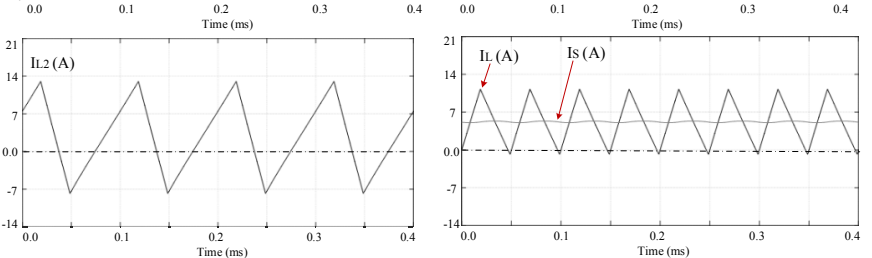

(b)

Fig.7. Simulated waveforms of the interleaved boost converter
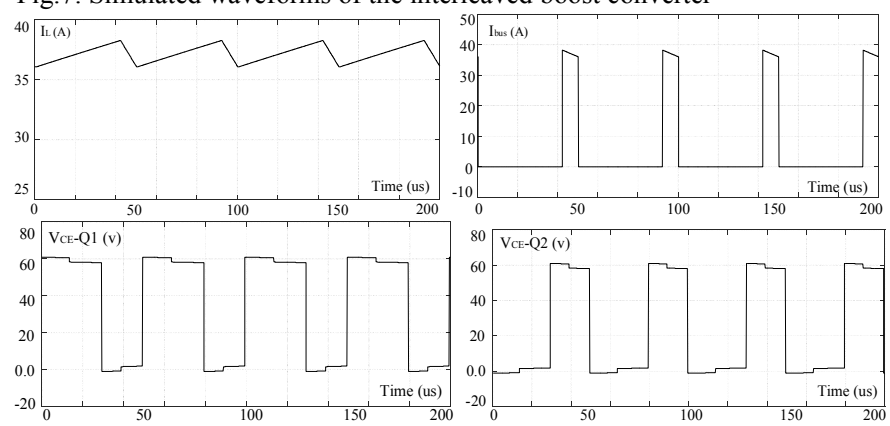

(a)
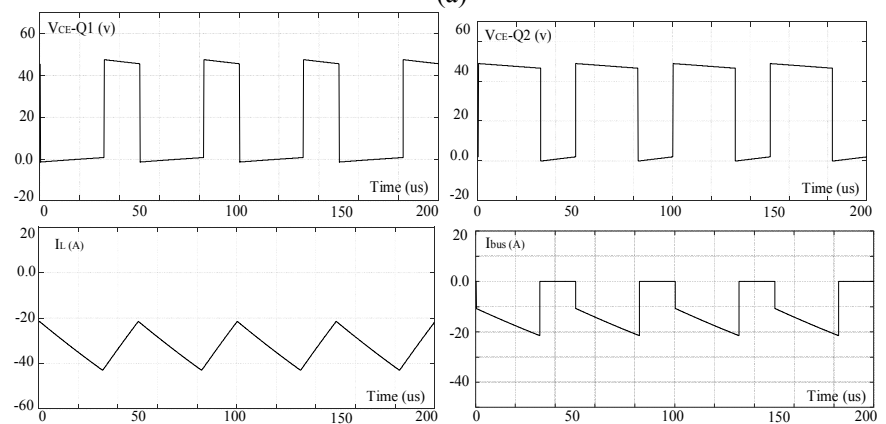

(b)

Fig.8. Simulated waveforms of the buck-boost bidirectional converte operating in (a)-boost or discharging mode, (b)-buck or charge mode

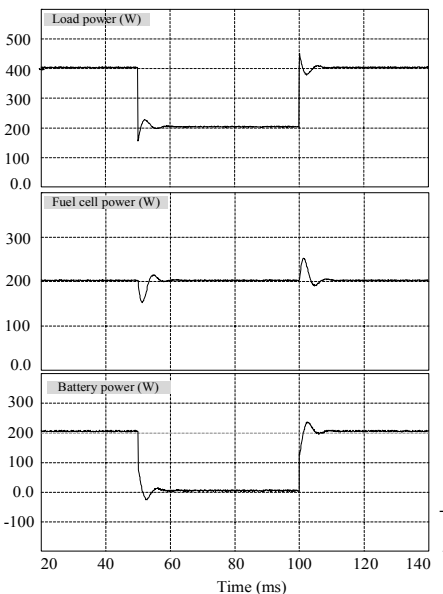

(a)

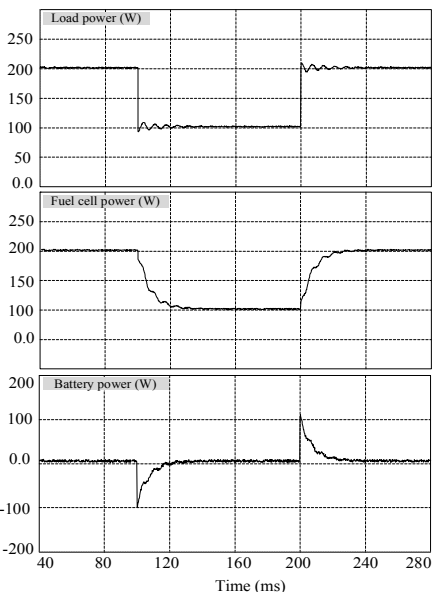

(b)
Fig.9 Simulation results of the TAB converter operation under load variation, (a) fuel cell is supplying a constant power and battery follows the load variations, and (b) fuel cell follows the load variation and battery operates as a compensator.

\section{REFERENCES}

[1] IPCC Fourth Assessment Report: Climate Change 2007, https://www.ipcc.ch/publications_and_data/ar4/wg1/en/tssts-3-11.html

[2] M. Jafari, G. Hunter and Jian Guo Zhu, "A new topology of multiinput multi-output Buck-Boost DC-DC Converter for microgrid applications," in Proc. IEEE Int. Conf. on Power and Energy (PECon), Kota Kinabalu, 2012, pp. 286-291.

[3] H.Tao, A. Kotsopoulos, J. L. Duarte and M. A. M. Hendrix, "TransformerCoupled Multiport ZVS Bidirectional DC-DC Converter With Wide Input Range," IEEE Trans. Power Electron., vol. 23, no. 2, pp. 771-781, March 2008

[4] C. Zhao, S.D.Round, and J.W.Kolar, "An isolated three-port bidirectional DC-DC converter with decoupled power flow management," IEEE Trans. Power Electron., vol. 23, no. 5, pp. 2443 2453, Sep. 2008

[5] M. Jafari, Z. Malekjamshidi, G. Platt, J. G. Zhu and D. G. Dorrell, “A multi-port converter based renewable energy system for residential consumers of smart grid," 41st Annual Conf. Ind. Electronics Society IECON 2015 -, Yokohama, 2015, pp.

[6] H. Tao, A. Kotsopoulos, J. L. Duarte, and M. A. M. Hendrix, "Family of multiport bidirectional DC-DC converters," IEE proceedings of Electric Power Applications, Vol.153, Issue: 3, pp.451-458, 2006

[7] M. Jafari, Z. Malekjamshidi, G. Lei, T. Wang, G. Platt and J. Zhu, "Design and Implementation of an Amorphous High-Frequency Transformer Coupling Multiple Converters in a Smart Microgrid," IEEE Trans. on Ind. Electronics, vol. 64, no. 2, pp. 1028-1037, Feb. 2017.

[8] S. Falcones, R. Ayyanar and X. Mao, "A DC-DC MultiportConverter-Based Solid-State Transformer Integrating Distributed Generation and Storage," IEEE Trans. Power Electron, vol. 28, no. 5, pp. 2192-2203, May 2013.

[9] M. W. Ahmad, N. Agarwal and S. Anand, "Online Monitoring Technique for Aluminum Electrolytic Capacitor in Solar PV-Based DC System," IEEE Trans. Ind. Electron., vol. 63, no. 11, pp. 70597066, Nov. 2016

[10] G. R. Chandra Mouli; J. Schijffelen; P. Bauer; M. Zeman, "Design and Comparison of a $10 \mathrm{~kW}$ Interleaved Boost Converter for PV Application Using Si and SiC Devices," IEEE Journal of Emerging and Selected Topics in Power Electron., vol. PP, no.99, pp.1-1,2016.

[11] B. Mangu, S. Akshatha, D. Suryanarayana and B. G. Fernandes, "Grid-Connected PV-Wind-Battery-Based Multi-Input TransformerCoupled Bidirectional DC-DC Converter for Household Applications," IEEE Journal of Emerging and Selected Topics in Power Electronics, vol. 4, no. 3, pp. 1086-1095, Sept. 2016.

[12] H. Wu, P. Xu, H. Hu, Z. Zhou and Y. Xing, "Multiport Converters Based on Integration of Full-Bridge and Bidirectional DC-DC Topologies for Renewable Generation Systems," IEEE Trans. Ind. Electron., vol. 61, no. 2, pp. 856-869, Feb. 2014.

[13] Y. Shi, R. Li, Y. Xue and H. Li, "High-Frequency-Link-Based GridTied PV System With Small DC-Link Capacitor and Low-Frequency Ripple-Free Maximum Power Point Tracking," IEEE Trans. Power Electronics, vol. 31, no. 1, pp. 328-339, Jan. 2016

[14] Haiping Xu, Xuhui Wen, Ermin Qiao, Xin Guo and Li Kong, "High Power Interleaved Boost Converter in Fuel Cell Hybrid Electric Vehicle," in proc IEEE Int. Conf. on Electric Machines and Drives, 2005., San Antonio, TX, 2005, pp. 1814-1819.

[15] O. Hegazy, J. V. Mierlo and P. Lataire, "Analysis, Modeling, and Implementation of a Multidevice Interleaved DC/DC Converter for Fuel Cell Hybrid Electric Vehicles," IEEE Trans. Power Electronics, vol. 27, no. 11, pp. 4445-4458, Nov. 2012.

[16] J.Zhang"Bidirectional DC-DC Power Converter Design Optimization, Modeling and Control," Ph.D. Dissertation, VPI\&SU, 2008.

[17] O. Ellabban, J. Van Mierlo and P. Lataire, "A DSP-Based Dual-Loop Peak DC-link Voltage Control Strategy of the Z-Source Inverter," IEEE Trans. Power Electron. vol. 27, no.9, pp.4088-4097, Sept. 2012.

[18] M. Jafari, G. Platt, Z. Malekjamshidi and J. G. Zhu, "Technical issues of sizing Lead-Acid batteries for application in residential renewable energy systems," in Proc. 4th Int. Conf. on Electric Power and Energy Conversion Systems (EPECS), Sharjah, 2015, pp. 1-6.

[19] B. Yang, W. Li, Y. Zhao and X. He, "Design and Analysis of a GridConnected Photovoltaic Power System," IEEE Trans. Power Electronics, vol. 25, no. 4, pp. 992-1000, April 2010. 